\title{
AACSB College Of Business Deans' Perception Of Selected Communication Competencies
}

\author{
Donald E. English, (E-mail: Donald_English@tamu-commerce.edu), Texas A\&M University, Commerce \\ Edgar Manton, Texas A\&M University, Commerce \\ Janet Walker, Texas A\&M University, Commerce
}

\begin{abstract}
The purpose of this study was to determine AACSB college of business deans' perception of selected communication competencies. The business communication competencies studied were 1. writing and speaking, 2. Interpersonal/collaborative competencies and 3. global communication competences. A questionnaire was developed and mailed to AACSB college of business deans. The study analyzed deans views on selected communication competencies. The questionnaire identified 44 competencies. The deans were asked to evaluate each of the listed 44 competencies. The two competencies that ranked the highest were "uses personal integrity in communication" and "spells correctly."
\end{abstract}

\section{INTRODUCTION}

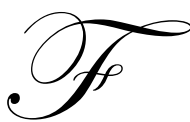

or years, research studies and journal articles have emphasized the importance of communication skills. Today these communication skills have become that much more essential in obtaining employment and advancing in a business career. What business communication skills are needed by university business graduates? The literature in recent years has been abundant concerning needed business communication skills and abilities. What business communication competencies do human resource managers believe are most important? Are colleges and universities providing graduates with the needed business communication competencies required in the business world?

\section{OBJECTIVES OF THE STUDY}

The main objective of this study is to determine AACSB deans' perceived value of selected business communication competencies.

\section{PROBLEM STATEMENT}

The problem of this study was to determine which business communication competencies deans view as most important. The business communication competencies studied include:

1. writing and speaking competencies

2. interpersonal/collaborative competencies and

3. global communication competencies.

\section{METHODOLOGY}

Communication skills used for this study were obtained from the following sources: various research studies identifying critical management skills, a locally developed College of Business and Technology advisory group listing of skills and knowledge essential for a business major, and from various journals and business 
communication textbooks. After identifying the business communication skills, a questionnaire was developed and mailed to AACSB college of business deans.. The following scale was used by deans to evaluate each competency: 4=Extremely Essential, 3=Highly Essential, 2=Essential, 1=Not Essential.

\section{RELATED LITERATURE}

The importance of communication skills in business has been recognized for years. The following studies are examples of the importance placed on communication skills in today's business world.

Curtis, Stephens, and Winsor sent a questionnaire to 1000 personnel managers from a list of members of The American Society of Personnel Administrators. Written and oral communications were the skills that were most useful in helping graduating college students obtain employment. "Clearly, personnel directors are calling for graduates with strong oral and written communication skills" (p.13). As reported by Gustafson, Johnson, and Hovey a survey was conducted by West Georgia College to determine the skill, abilities, knowledge, and traits important for business students to obtain and advance in employment. BBA and MBA alumni, business leaders, and current senior BBAs were surveyed. "All groups surveyed placed communication skills (writing and speaking) as the two most important general skills" (p. 23).

According to Murphy and Hildebrand, many surveys and articles "have confirmed the idea that effective communication is essential for success and promotion in business" (p. 8). When executive, managers and business graduates were asked "What has been the most valuable subject you studied in college?" "Business communication, business letter and report writing, and written and oral Expression were consistently among the top three responses... and executive often credit good communication skills for their advancement" (p. 8).

Lesikar emphasizes the importance of communication skills in the present business environment indicating that "business's need for employees with good communication skills is all too often not fulfilled. Most employees, even the college trained, do not communicate well" (p. 3). Angell states "Every business-whether a multibilliondollar company... or a small family-owned grocery store - relies on the communication skills of its employees to be successful" (p. 4). DuFrene reports that "studies have shown that managers spend approximately 60 to 80 per cent of their time involved in some form of communication" (p. 4). Bovee and Thill report "Effective communication is at the center of virtually every aspect of business because it connects the company with all its stakeholders..." (p. 4).

In her article "Managing in the 90's", Patricia Buhler emphasizes the importance of communication. She reports that "communication remains a critical element of an organization's success... and the majority of managers report communication issues to be the number 1 problem they face" (p. 23). Bennington also provides some insight when she states "Employers consistently identify communication skills (written and oral) as critical for employee and business success. In addition to employer expectations, institutions must be responsive to accreditation requirement. The major business program accrediting organization-Association for the Advancement of Collegiate Schools of Business- International (AACSB) has identified communication abilities as important general skills for institutions to incorporate into program learning outcomes and assessment.

\section{PROCEDURE}

A questionnaire was prepared containing 44 selected communication competencies. The communication competencies were categorized into three classifications of communication competencies in order to place the competency into a frame of reference for the respondents to consider. Following are the categories:

1. writing and speaking communication competencies

2. interpersonal and collaborative communication competencies

3. global communication competencies 
Deans were asked to evaluate the importance of the each communication competency for new business majors as: 4 = extremely essential; $3=$ essential; 2 = needed, but can be learned on the job; and $1=$ not essential. From the responses, a mean score for each communication competency was calculated.

The questionnaires were mailed to AACSB college of business deans. Of the 440 questionnaires, 121 were returned for a response rate of $28 \%$. Of these 121 surveys returned, 116 were usable.

\section{FINDINGS AND ANALYSIS}

The means for the 44 competencies were calculated and were listed in rank order without consideration for the category in which they were included. The intent was to develop a ranking for the communication competencies without regard to the communication competency categories. The competencies and the averages of the deans' evaluation scores are indicated on Table 1, page 12.

It seems that the top ranked competencies by the deans can be classified into three categories. Considering the ten competencies that received the highest scores, two of the top three identified by the deans dealt with integrity and confidentiality in communications. Five dealt with effectiveness of written communication, and three competencies related to communicating and interacting effectively with others.

The highest scored competency was "personal integrity in all communications." Coming in third on the list was "appropriate confidentiality." In view of the recent corporate scandals, it seems appropriate for the deans to focus on the importance of these factors in business communication. In prior years, it is doubted that these factors would have received the highest score for communication competencies needed by business graduates.

In the next category, the deans strongly supported the need for well organized, clear, well written, and effectively focused documents. The competencies ranked $2^{\text {nd }}, 4^{\text {th }}, 6^{\text {th }}$, and $8^{\text {th }}$, all related to written communication. Thus, the deans seem to believe that it is important for business majors to possess strong writing skills when he or she enters the job market. The competencies ranked $2^{\text {nd }}, 4$ th, $6^{\text {th }}$, and $8^{\text {th }}$ are "spelling"; "punctuation and grammar"; "effective proofreading"; and "neat, attractive, and well organized documents." Many studies have shown college graduates to be lacking skills in spelling, punctuation and grammar. The need to focus "on the main idea in a message" is ranked fifth by the deans. Tied for the tenth ranked competency is "knowledge of general principles of writing effective business communication". All of these competencies relate to an effectively written business communication.

The next highest level of competencies deals with communicating and interacting effectively with other work related contacts. These competencies were ranked $7^{\text {th }}, 9^{\text {th }}$, and one which was tied for $10^{\text {th }}$ position. The seventh ranked competency was "interacts in a positive, productive, and thoughtful way." The ninth dealt with "understands the importance of business relationships with...." all company stakeholders. And the $10^{\text {th }}$ factor is "collaborates effectively in groups and on teams."

Thus, the college of business deans' most important communication competencies needed by a business college graduate may be placed in one of three categories:

1. integrity and appropriate confidentiality in communication

2. knowledge of and use of effective writing principles, including grammar, spelling, and punctuation

3. understanding business relationships and interacting in a positive manner.

While some of the competencies received lower evaluation by the deans none of the scores on a four point scale indicated on Table 1, page 12 are considered to be low. The lower scored competencies are not deemed as essential by the deans as those previously discussed. Some of the lowest evaluated competencies deal with intercultural or international issues - "possesses sensitivity to the language values and behaviors of other cultures," "understanding importance of intercultural business practices and customs" "uses appropriate communication skill to share messages with someone whose first language is not English," "demonstrates intercultural communication 
competency." Two other competencies receiving low scores were "understands and exercises conflict resolution strategies and techniques," and knowledge of distance communication technologies." Again, a 2.5 on a 4 point scale does not necessarily mean a low score, but it is the lowest score recorded among the competencies considered.

Thus it would appear that deans want business school graduates who appreciate and understand integrity and confidentiality in communication and those who are capable of preparing neat documents which are focused on message and which have been carefully prepared and reviewed and which contain proper grammar without errors in punctuation or in spelling. According to this study, perhaps colleges should deal with communication with persons from other cultures, and the ability to use technology in communicating, but high levels of these competencies are not essential for initial employment and training. It would seem that competencies in these skills beyond a basic level should be corporate specific and as such should appropriately be provided by the corporation when needed.

\section{SUMMARY AND CONCLUSIONS}

AACSB college of business deans were surveyed to determine their views of the communication competencies they feel are essential for recent business college graduates to possess. There were 121 responses.

The questionnaire identified 44 communication competencies for which the respondents were asked to indicate how essential the competency was for a new business graduate to possess to be employed. The average responses to each competency was calculated.

The deans indicated that personal integrity in all communication, correct spelling, and maintains confidentiality in communication were the highest traits needed for recent business college graduates. In addition, the respondents indicated that the business major should be able to use correct grammar, punctuation, and spelling, focus on the main idea of the message, effectively proofread, and use neat and well-organized documents. These were followed by the need to proofread documents and understanding the principles of effective communication. Also highly rated were communication skills that permit effective interaction and understanding business relationships. The most important competencies indicated by the deans seem to fit into three categories: ethical and confidential communication, accurate, focused and well prepared communication, and effective interaction with others in communication. These then are the competencies that deans indicate that business schools should emphasize in order to improve the employability of their graduates.

Factors which were still important but which received lower ratings than the above factors were those competencies dealing with evaluating audiences, international and intercultural communication, and in distance communications.

In view of the recent corporate scandals it is not surprising that deans would place a heavy emphasis on competencies related to communication integrity and appropriate confidentiality. Also the high ratings for neat appearing documents which have correct spelling, and correct use of grammar and punctuation is not surprising in view of many studies indicating the college graduate is weak on these factors.

When considering curriculum revisions and changes, the views of deans is an essential input. The deans in many cases, have an influence on curriculum development The input of the deans on communication competencies would be an essential consideration in a curriculum review involving communication skills required for the entrylevel business major. Of course, other constituencies must also be considered in this matter. Standards established by accrediting agencies must be factored into any review of the curriculum. Human recourse managers and the college faculty involved in teaching communication curriculum content must be included in discussions concerning the communication curriculum. Also, valuable input would be provided by college advisory councils. Any complete study of the communications competencies and skills required of the business graduate must consider all of these stakeholders. 
Table 1

$\begin{array}{lc}\text { Communication Competencies } & \text { Weighted } \\ \text { Average }\end{array}$

Average

1. Uses personal integrity in all communication (includes all relevant information, and does not present any deceptive information).

2. Spells correctly.

3. Maintains appropriate confidentiality.

4. Punctuates and uses correct grammatical written communication.

5. $\quad$ Effectively focuses on the main idea in the message.

6. Effectively proofreads, edits, and revises written communication.

7. Interacts in a positive, productive, and thoughtful way 3.496

8. Recognizes the importance of neat, organized, and attractive written documents. 3.432

9. Understands the importance of business relationships withsuperiors, coworkers, subordinates, customers, vendors, and other business associates.

10. Knowledge of general principles of writing effective business communication.

11. Collaborates effectively in groups and on teams.

12. Writes effective résumés and letters of application.

13. Writes well-organized paragraphs (words, strong language, abbreviations etc).

14. Avoids stereotyping people from other cultures, and understands their norms and values.

15. Makes decisions and solves problems cooperatively with others.

16. Effectively delivers an oral presentation.

17. Writes effective short reports.

18. Writes concisely (leaves out unnecessary words and phrases).

19. Uses eye contact effectively.

20. Writes effective letters.

21. Demonstrates appropriate social courtesy and etiquette.

22. Uses appropriate nonverbal behavior (kinesics, occulesics, personal appearance, paralanguage, and proxemics, etc.).

23. Writes effective business e-mail messages without emotions and cyber speak abbreviations.

24. Uses a clear, distinct, and pleasant speaking style.

25. Effectively uses persuasion and builds strong arguments. 
27. Writes strong messages (with active verbs and concrete words). 3.034

28. Exercises empathy by understanding how readers may interpret written messages.. $\quad 3.008$

29. Writes from the standpoint of the reader's interests and benefits. 2.991

30. Learns appropriate professional and social behaviors of the culture with which he or she $\begin{array}{ll}\text { is communicating. } & 2.983\end{array}$

$\begin{array}{ll}\text { 31. Uses varied and appropriate vocabulary. } & 2.974\end{array}$

32. Proficient research and data collection, analytical, and interpretation skills. 2.966

33. Possesses skills in informal business and social conversation. 2.966

34. Knows how to use and interpret tabular and graphic data. 2.957

35. Possesses sensitivity to the language values and behaviors of other cultures. 2.940

36. Understands the importance of intercultural business practices and customs. 2.931

37. Uses appropriate communication skills to share messages with someone whose first
language is not English.

38. Demonstrates leadership abilities. $\quad 2.907$

$\begin{array}{ll}\text { 39. Writes effective long reports. } & 2.864\end{array}$

40. Organizes and develops effective speeches. 2.863

41. Demonstrates intercultural communication competence. 2.839

$\begin{array}{ll}\text { 42. Effectively evaluates audiences. } & 2.829\end{array}$

43. Understands and exercises conflict resolution strategies and techniques. 2.779

44. Knowledge of distance communication technologies. 2.496

\section{REFERENCES}

1. Angell, Pamela. (2004) Business Communication Design, Irwin McGraw-Hill, New York.

2. Bennington, Ashley. (2005) Our Students' Audiences: What Do Employers and Faculty Really Want? Retrieved May 2005, http://www.google.com/search.

3. Bovee, Courtland and Thill, John. (2005) Business Communication Today. Eighth Edition, Prentice Hall, New Jersey.

4. Buhler, Patricia. (1997). Managing in the 90’s. Supervision 23-26.

5. Curtis, DB, Winsor, J.L. and Stephens, R. D. (1989) National Preferences in Business and Communication Education. Communication Education, 38 6-14.

6. Gustafson. L.V., Johnson, J. E., and Hovey, D. H. (1993) Preparing Business Students—can we Market Them Successfully Business Education Forum, 23-26.

7. Lehman, C.M. and DuFrene, D.D. (1999). Business Communication, $12^{\text {th }}$ Edition, Southwestern, Cincinnati.

8. $\quad$ Lesikar, R. V., and Flately, M. E. (2005) Basic Business Communication. 10 ${ }^{\text {th }}$ Edition, McGraw-Hill, New York.

9. $\quad$ Murphy, H.A., Hildebrandt, and H.W., Thomas, J.P. (1997) Effective Business Communications $7^{\text {th }}$ Edition, McGraw-Hill, New York. 